\title{
Influence of dynamics of development of open mining on technological features of blasting breaking
}

\author{
Sergey Zharikov ${ }^{1 *}$ and Vyacheslav Kutuev ${ }^{1}$ \\ ${ }^{1}$ Institute of Mining, Ural Branch of the Russian Academy of Sciences, Ekaterinburg, Russia.
}

\begin{abstract}
The paper desribes the results of the analysis of the drilling and blasting index at some large enterprises. The significant period of their work has been considered. The increase in the specific consumption of explosives by years has been shown and the reasons for this increase have been explained. The issue of the development prospects of the drilling and blasting complex in terms of reducing the cost of explosives, as well as some issues associated with the use of explosives, manufactured on site. It is suggested that in the near future the development of open mining will be associated with the acceleration of processes and a significant increase in their intensity, both in the development of new ones and in the refinement of existing large open-pit mines. In this regard, drilling and blasting operations are waiting for certain changes in both the mechanization of processes and the technological methods of production. An approach is proposed for improving energy efficiency and resource saving in the production of drilling and blasting operations, which consists in applying a horizontal cut along the bottom of the bench with blasting breaking of the rock mass. It has been previously shown that the use of this method of breaking can be quite effective in comparison with the traditional approach. Key words: drilling and blasting operations, explosive materials, horizontal cut, specific consumption of explosives, explosive breaking, horizontal drilling.
\end{abstract}

\section{Introduction}

Currently, in large open-pit mines, the DBO costs are $30 \%$ of total production costs and are expected to be increased as mining is reduced. From 1975 to 2015 the Institute of Mining of the Ural Branch of RAS had accumulated a significant amount of data on the BDO of iron ore and building material open-pit mines, which makes it possible to estimate the dynamics of changes in production indicators and to establish the trend of their progress in the future. It should be noted that the Uralasbest plant has data only since 1990. For the analysis, it was assumed that earlier indicators were at the level of the specified year. Therefore, a comparison of the DBO indicators and their averaging for the estimation of the dynamics of

\footnotetext{
*Corresponding author: $\underline{33 \text { vista@mail.ru }}$
} 
change has been carried out for 9 MPS and separately for 8 MPS of iron ore deposits without taking into account the data of the Uralasbest combine.

\section{Theory}

Figures 1 - 3 show that the most significant increase in the specific consumption of explosives is traced from 1988-1990. Approximately at this point, the widespread use of explosives manufactured on site, the specific consumption of which is higher than for standard explosives by $10-20 \%$ due to the density of matter. For each enterprise, this time was different, and also the increase in the specific consumption of explosives is different. However, taking into account the recalculation for standard explosive, the specific consumption of explosives has grown quite significantly, although in general the costs for explosive materials have decreased due to their cost. The introduction of explosives produced on site has significantly improved the economy of mining enterprises. At the same time, the way of breaking the excavating blocks remained practically unchanged. So the underestimation of pre-destructive impact in the rear of the rock mass resulted in some cases in a deterioration in the quality of crushing, which adversely affected the efficiency of drilling and blasting operations.

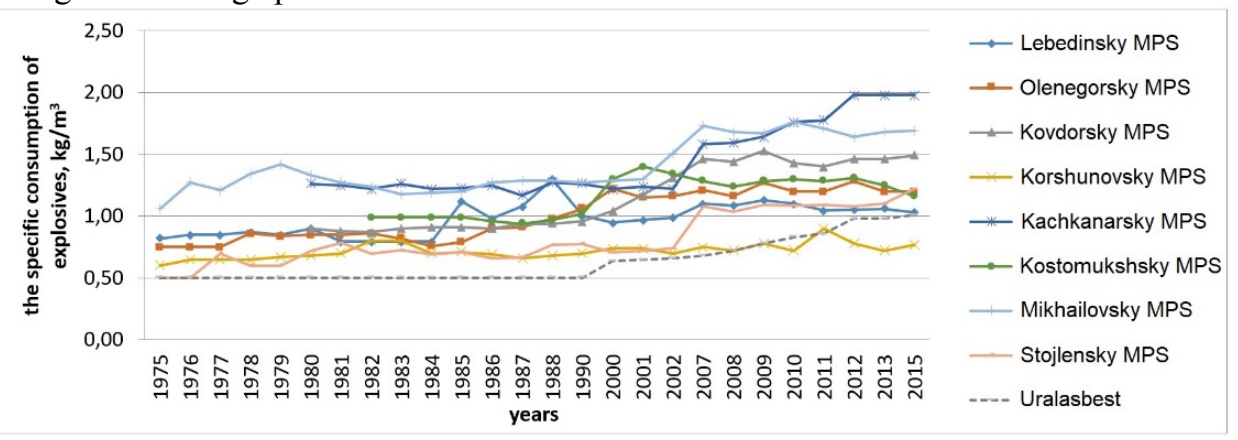

Fig. 1. Dynamics of change in specific consumption of explosives for 9 large MPS.

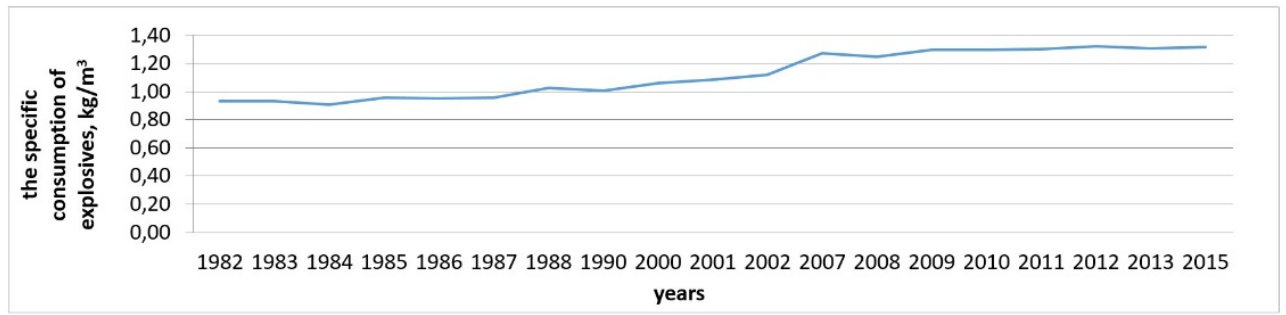

Fig. 2. Average dynamics of change in specific consumption of explosives for 8 large MPS in ironmining industry.

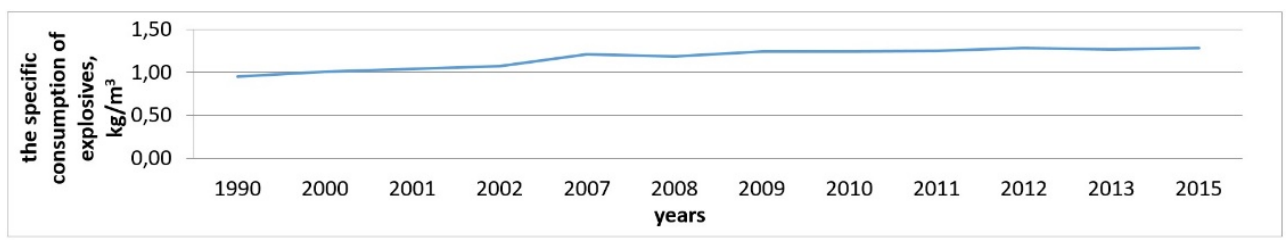

Fig. 3. Dynamics of change in specific consumption of explosives for 9 large MPS.

Change in the sphere of drilling operations is characterized by a steady increase in both drilling volumes and weighted average productivity. It is noted that the use of highperformance machines of foreign production does not always reflect the efficiency of 
technological solutions [2]. Therefore, an important technological issue of the near-term perspective at the final extraction of deposits is the utilization rate of the drilling rig.

Increasing the efficiency of drilling and blasting operations in general is represented in the reduction of costs. This approach is traditional, and as time shows, it results in the improvement not only of the production of technological explosions, but also of other mining operations. The analysis allows to draw a conclusion that if the goal is to reduce the costs of drilling and blasting operations, first of all it is necessary to reduce the main indicator - the specific consumption of explosives. The methods can be different. First of all, these are charge structures determined on the basis of the rapid study of the physical and mechanical properties of rock mass of excavating blocks prior to the charging process [3 - 5]; a variable array of boreholes installed directly in the process of drilling off the block [6]; as well as the technology for breaking off the excavation blocks, for example, using horizontal drilling (the question has not been practically investigated).

For a long time, it was believed that in order to improve the quality of crushing of very hard-shot viscous rocks, it is sufficient to increase the specific consumption of explosives. However, as practice shows, the narrowing of the borehole array and the increase in the specific consumption of explosives do not result in improvement of the crushing quality [7]. As a result, material resources are not spent efficiently. In support of this, an approximate calculation of the effect of the explosion at a distance from the charge has been made. For the calculation, the dependencies indicated in [1, $8-9]$ have been used .

Pressure on the wall of the borehole:

$$
P=\frac{r_{c h r g}^{2}}{2 r_{b h}^{2}} \cdot \frac{\rho_{\exp } \cdot \mathrm{D}^{2}}{4},
$$

where $r_{\text {chrg }}$ - charge radius, $\mathrm{m} ; \mathrm{r}_{\mathrm{bh}}$ - borehole radius, $\mathrm{m} ; \mathrm{P}_{\mathrm{d}}$ - detonation wave pressure, $\mathrm{MPa} ; \rho_{\text {exp }}$ - explosive density, $\mathrm{kg} / \mathrm{m}^{3}$; D - detonation velocity, $\mathrm{m} / \mathrm{s}$.

Pressure in the rock mass from the explosion of a cylindrical charge at a distance:

$$
P_{R}=P\left(\frac{r_{b h}}{R}\right)^{1,5},
$$

where $\mathrm{R}$ - distance from charge explosion, $\mathrm{m}$

In the calculation, the diameter of the borehole is $250 \mathrm{~mm}$. The diameter of the borehole and the diameter of the charge are equal. The results are shown in Table 1. According to Table 1 , after only $1 \mathrm{~m}$, the pressure drops by $96 \%$ for all explosives. Let us consider an example for granulotol:

$$
\frac{3125-138,11}{3125} 100 \%=96 \% .
$$

At a distance of $2 \mathrm{~m}$ from the charge, the pressure drops by $98 \%$, and at a distance of 3 $\mathrm{m}$ - by $99 \%$. The indicated distances correspond approximately to the zone of controlled crushing, which is expressed by 4-8 charge diameters [10]. With a charge of $250 \mathrm{~mm}$, the zone of controlled crushing is $1-2 \mathrm{~m}$. In this case, according to [10], the cracking zone amounts to 15 - 30 charge diameters, in our case it is 3.5 - 7.5 meters. If, as an example, we consider a rock with a limit strength in the sample: in compression being $200 \mathrm{MPa}$, in expansion being $20 \mathrm{MPa}$, and a coefficient of structural weakening in the rock mass being 0.1 (respectively, compression in rock mass being $20 \mathrm{MPa}$, expansion being $2 \mathrm{MPa}$ ), then the pressure from explosion in many explosives (see Table 1) overcomes the compressive stresses by 3 - $4 \mathrm{~m}$ from the charge, and expanding being up to $10 \mathrm{~m}$.

Therefore, it is advisable to keep the distances between the boreholes in the block unchanged, and vice versa, to maximize the possible value (reduce the specific consumption of the explosive). 
Table 1. Pressure at a distance from the explosion of certain explosives

\begin{tabular}{|c|c|c|c|c|c|c|c|c|c|c|c|c|c|}
\hline \multirow{3}{*}{ Explosive } & \multirow{3}{*}{$\begin{array}{c}\text { Detonation } \\
\text { velocity, } \\
\mathrm{m} / \mathrm{s}\end{array}$} & \multirow{3}{*}{$\begin{array}{c}\text { Load } \\
\text { density of } \\
\text { explosive, } \\
\mathrm{g} / \mathrm{cm}^{3}\end{array}$} & \multirow{3}{*}{$\begin{array}{c}\text { Pressure } \\
\text { on the } \\
\text { walls of } \\
\text { the } \\
\text { borehole, } \\
\text { MPa }\end{array}$} & \multicolumn{10}{|c|}{ Pressure from explosion, $\mathrm{MPa}$} \\
\hline & & & & \multicolumn{10}{|c|}{ Distance from charge, $\mathrm{m}$} \\
\hline & & & & 1 & 2 & 3 & 4 & 5 & 6 & 7 & 8 & 9 & 10 \\
\hline granulotol & 5000 & 1 & 3125.0 & 138.11 & 48.83 & 26.58 & 17.26 & 12.35 & 9.40 & 7.46 & 6.10 & 5.12 & 4.37 \\
\hline gramonite $79 / 21$ & 3700 & 0.9 & 1540.1 & 68.06 & 24.06 & 13.10 & 8.51 & 6.09 & 4.63 & 3.68 & 3.01 & 2.52 & 2.15 \\
\hline poremite $1 \mathrm{~A}$ & 5000 & 1.2 & 3750.0 & 165.73 & 58.59 & 31.89 & 20.72 & 14.82 & 11.28 & 8.95 & 7.32 & 6.14 & 5.24 \\
\hline Nitronite E-70 & 4500 & 1.2 & 3037.5 & 134.24 & 47.46 & 25.83 & 16.78 & 12.01 & 9.13 & 7.25 & 5.93 & 4.97 & 4.25 \\
\hline siberite & 4800 & 1.25 & 3600.0 & 159.10 & 56.25 & 30.62 & 19.89 & 14.23 & 10.83 & 8.59 & 7.03 & 5.89 & 5.03 \\
\hline granemite I-30 & 5000 & 1.35 & 4218.8 & 186.44 & 65.92 & 35.88 & 23.31 & 16.68 & 12.69 & 10.07 & 8.24 & 6.91 & 5.90 \\
\hline fortis edv. 80 & 5510 & 1.1 & 4174.5 & 184.49 & 65.23 & 35.50 & 23.06 & 16.50 & 12.55 & 9.96 & 8.15 & 6.83 & 5.83 \\
\hline emulsolite & 5000 & 1.25 & 3906.3 & 172.63 & 61.04 & 33.22 & 21.58 & 15.44 & 11.75 & 9.32 & 7.63 & 6.39 & 5.46 \\
\hline slarrite & 5000 & 1.25 & 3906.3 & 172.63 & 61.04 & 33.22 & 21.58 & 15.44 & 11.75 & 9.32 & 7.63 & 6.39 & 5.46 \\
\hline emulogram & 4500 & 1.3 & 3290.6 & 145.43 & 51.42 & 27.99 & 18.18 & 13.01 & 9.90 & 7.85 & 6.43 & 5.39 & 4.60 \\
\hline emulite VET 500 & 4600 & 1.35 & 3570.8 & 157.81 & 55.79 & 30.37 & 19.73 & 14.11 & 10.74 & 8.52 & 6.97 & 5.84 & 4.99 \\
\hline
\end{tabular}

As approximate calculations show, in principle it is possible to increase the distance between boreholes in strong rocks to $8-10$ meters or more, if the issue is solved with the development of the resistance line on the bottom of the bench. At large distances between the boreholes, the issue of developing the bottom is decisive. As an alternative of the solution of this question, horizontal cutting can be used. Thus, the bottom can be developed without the use of vertical re-drills.

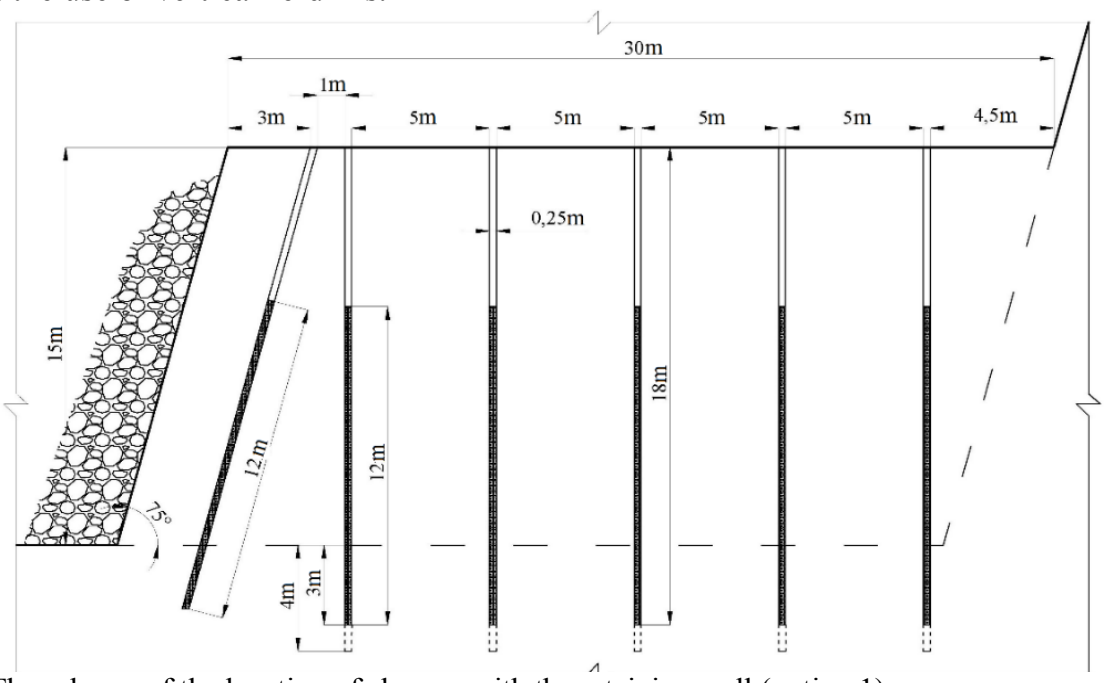

Fig. 4. The scheme of the location of charges with the retaining wall (option 1).

Below are the results of an approximate estimation of the efficiency of the concept of horizontal cutting (option 2) compared to conventional breaking technology (option 1). The conditions for estimating the options are as follows. The rock mass is composed of strong rocks with an average coefficient of strength 14 . The ultimate strength in the sample for compression is $140 \mathrm{MPa}$, the tensile strength being $14 \mathrm{MPa}$, the density of rocks being 3.5 $\mathrm{t} / \mathrm{m}^{3}$, the coefficient of structural weakening in the rock mass being 0.1 . Length excavating block $120 \mathrm{~m}$. The explosive is Nitronite E-70 (charge density being $1.2 \mathrm{~g} / \mathrm{cm}^{3}$ ). Parameters (option 1) are shown in figure 4. In addition: the borehole diameter being $250 \mathrm{~mm}$, the borehole array being $6 \times 5 \mathrm{~m}$, blasting on the retaining wall.

For option 2 of breaking parameters are defined in accordance with the value of the cracking radius using a specific explosive (expression (1) and (3)). 
Cracking radius [5]:

$$
R_{m p}=r_{h} \sqrt[3]{\left(P / \sigma_{\mathrm{dyn}}\right)^{2}},
$$

where $r_{h}$ - borehole radius, $\mathrm{m}$; $\mathrm{P}$ - pressure on the borehole walls, MPa; $\sigma_{\text {дин }}$ - dynamic strength of rock, MPa (adopted $0.13 \sigma_{\mathrm{p}}=1.82 \mathrm{MPa}$ ).

Table 2. The cracking radius at $\sigma_{\text {дин }}=1.82 \mathrm{MPa}$

\begin{tabular}{|c|c|c|c|c|c|c|c|c|c|c|}
\hline \multirow{3}{*}{ Explosive } & \multicolumn{10}{|c|}{ Cracking radius, $\mathbf{m}$} \\
\hline & \multicolumn{10}{|c|}{ Parameters of charges $\mathrm{D}_{\text {скв }} / \mathrm{d}_{\text {зар }}$} \\
\hline & $90 / 90$ & $110 / 90$ & $120 / 90$ & $160 / 90$ & $110 / 110$ & $120 / 110$ & $160 / 110$ & $120 / 120$ & $160 / 120$ & $160 / 160$ \\
\hline granulotol & 6.5 & 6.0 & 5.9 & 5.3 & 7.9 & 7.7 & 7.0 & 8.6 & 7.8 & 11.5 \\
\hline gramonite 79/21 & 4.0 & 3.8 & 3.7 & 3.3 & 4.9 & 4.8 & 4.3 & 5.4 & 4.9 & 7.2 \\
\hline poremite $1 \mathrm{~A}$ & 7.3 & 6.8 & 6.6 & 6.0 & 8.9 & 8.7 & 7.9 & 9.7 & 8.8 & 13.0 \\
\hline Nitronite E-70 & 6.3 & 5.9 & 5.8 & 5.2 & 7.7 & 7.5 & 6.8 & 8.4 & 7.7 & 11.3 \\
\hline siberite & 7.1 & 6.6 & 6.4 & 5.9 & 8.7 & 8.4 & 7.6 & 9.5 & 8.6 & 12.6 \\
\hline granemite I-30 & 7.9 & 7.4 & 7.2 & 6.5 & 9.6 & 9.4 & 8.5 & 10.5 & 9.5 & 14.0 \\
\hline fortis edv. 80 & 7.8 & 7.3 & 7.1 & 6.5 & 9.6 & 9.3 & 8.4 & 10.4 & 9.5 & 13.9 \\
\hline emulsolite & 7.5 & 7.0 & 6.8 & 6.2 & 9.2 & 8.9 & 8.1 & 10.0 & 9.1 & 13.3 \\
\hline slarrite & 7.5 & 7.0 & 6.8 & 6.2 & 9.2 & 8.9 & 8.1 & 10.0 & 9.1 & 13.3 \\
\hline emulogram & 6.7 & 6.2 & 6.1 & 5.5 & 8.2 & 7.9 & 7.2 & 8.9 & 8.1 & 11.9 \\
\hline emulite VET 500 & 7.1 & 6.6 & 6.4 & 5.8 & 8.6 & 8.4 & 7.6 & 9.4 & 8.5 & 12.5 \\
\hline granulite igdanit & 2.5 & 2.4 & 2.3 & 2.1 & 3.1 & 3.0 & 2.7 & 3.4 & 3.1 & 4.5 \\
\hline
\end{tabular}

The data in Table 2 allows you to select the explosive and the most rational design of the cuttings. The selection of explosives implies the provision of the smallest fracture zone, so in this case the cracking radius should be minimal. Otherwise, the effect of the cut-off slot on the lower horizon will be comparable with the effect of the overdrills. In this case, vertical boreholes can be underdrilled to the bottom since in this area cuttings work.

According to the data in Table 2, gramonite 79/21 and granulite igdanite have the smallest radii of cracking. With these explosives, the underdrill can average $2-4 \mathrm{~m}$. The most acceptable is the diameter of the charge of $90 \mathrm{~mm}$. This diameter ensures the smallest cracking and reduces the likelihood rambling. Thus, the ratios accepted for further calculation are 90/90,110/90, 120/90. The results are shown in Table 3.

Table 3. Calculation of pressure from explosion of charge of cut slot at a distance

\begin{tabular}{|c|c|c|c|c|c|c|c|c|c|c|}
\hline \multirow{4}{*}{\multicolumn{2}{|c|}{ Charge parameters }} & \multicolumn{9}{|c|}{ Pressure from explosion of contour charge at a distance, $\mathrm{MPa}$} \\
\hline & & \multicolumn{9}{|c|}{ Explosive being granulit Igdanite } \\
\hline & & \multicolumn{9}{|c|}{ Distance, $\mathrm{m}$} \\
\hline & & 1 & 2 & 3 & 4 & 5 & 6 & 7 & 8 & 9 \\
\hline D borehole, $\mathbf{m m}$ & 90 & & & & & & & & & \\
\hline D charge, $\mathrm{mm}$ & 90 & 7.39 & 2.61 & 1.42 & 0.92 & 0.66 & 0.50 & 0.40 & 0.33 & 0.27 \\
\hline D borehole, $\mathbf{m m}$ & 110 & & & & & & & & & \\
\hline D charge, $\mathrm{mm}$ & 90 & 6.69 & 2.36 & 1.29 & 0.84 & 0.60 & 0.46 & 0.36 & 0.30 & 0.25 \\
\hline D borehole, $\mathrm{mm}$ & 120 & & & & & & & & & \\
\hline D charge, $\mathrm{mm}$ & 90 & 6.40 & 2.26 & 1.23 & 0.80 & 0.57 & 0.44 & 0.35 & 0.28 & 0.24 \\
\hline & & \multicolumn{9}{|c|}{ Explosive substance being grammonite $79 / 21$} \\
\hline D borehole, $\mathrm{mm}$ & 90 & & & & & & & & & \\
\hline D charge, $\mathrm{mm}$ & 90 & 14.70 & 5.20 & 2.83 & 1.84 & 1.31 & 1.00 & 0.79 & 0.65 & 0.54 \\
\hline D borehole, $\mathrm{mm}$ & 110 & & & & & & & & & \\
\hline $\mathrm{D}$ charge, $\mathrm{mm}$ & 90 & 13.30 & 4.70 & 2.56 & 1.66 & 1.19 & 0.90 & 0.72 & 0.59 & 0.49 \\
\hline D borehole, $\mathrm{mm}$ & 120 & & & & & & & & & \\
\hline D charge, $\mathrm{mm}$ & 90 & 12.73 & 4.50 & 2.45 & 1.59 & 1.14 & 0.87 & 0.69 & 0.56 & 0.47 \\
\hline
\end{tabular}

The data in Table 3 show that in order to overcome the tensile stresses $1.4 \mathrm{MPa}$, the distances as follows. For grammonite $79 / 21$ at a ratio $D_{\text {скв }} / d_{\text {зар }} 90 / 90$ are equal $4 \mathrm{~m}$ with charging each borehole or $3 \mathrm{~m}$ with charging the next but one. The same is true for other borehole diameters. For grammonite igdanit at a ratio $D_{\text {скв }} / d_{3 а р} 90 / 90$ are equal $3 \mathrm{~m}$ with charging each borehole or $2 \mathrm{~m}$ with charging the next but one. In other cases, is equal to 2 $\mathrm{m}$ with charging of each borehole. The distances between the boreholes for the maximum 
productivity of the machine should be as high as possible, therefore adopted the gramonite $79 / 21$ at a ratio $D_{\text {скв }} / d_{\text {зар }} 90 / 90$. According to Table 1 , the pressure at the explosion of nitronite E-70 at a distance of $4 \mathrm{~m}$ from the charge exceeds the compressive strength in the rock mass, therefore the distances between between the rows boreholes can be up to $8 \mathrm{~m}$. Is assumed to be $7.5 \mathrm{~m}$, that between the boreholes in the row being $8 \mathrm{~m}$. The rational size of the underdrill is determined by the length of the drill rods, the properties of rocks and the properties of explosives. In our case discussed a SBSH-250 machine. The length of the rod is usually $8 \mathrm{~m}$ (the first bar drills at $6 \mathrm{~m}$ ). Two bars $14 \mathrm{~m}$.

Parameters (option 1) are shown in figure 5. In addition, the distance between horizontal boreholes cut is $3 \mathrm{~m}$ with charging the next but one.

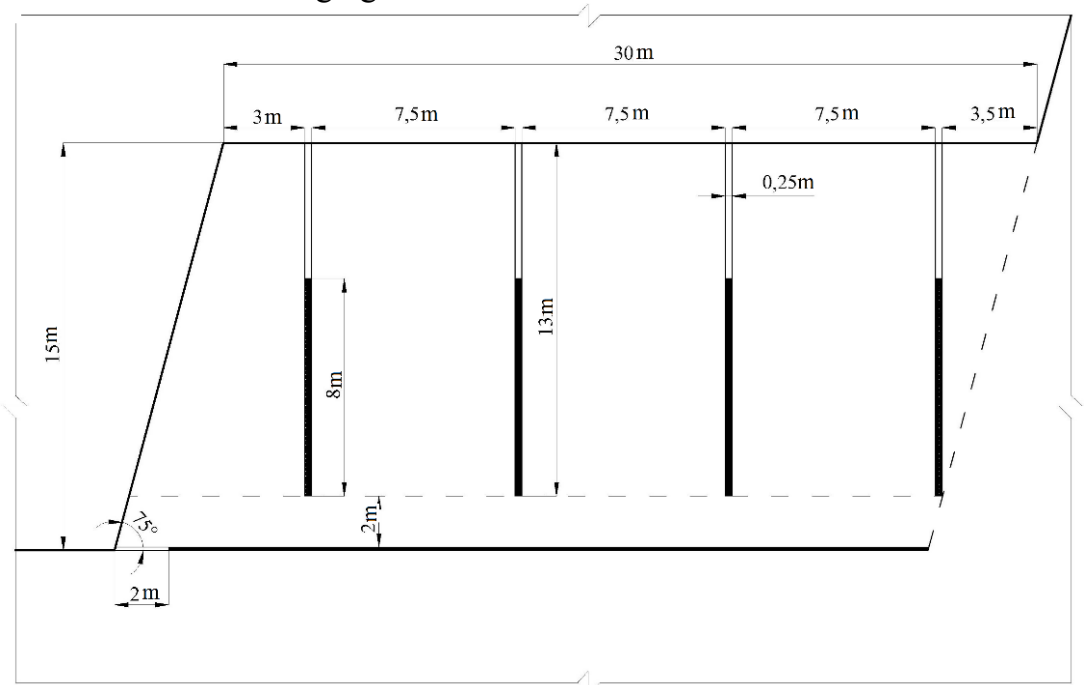

Fig. 5. The scheme of the location of charges for horizontal cut on the bottom of the bench.

\section{Results}

The approximate calculations presented in Table 4 show that the use of the method of breaking the extraction block with horizontal cut along the bottom of the bench can be quite efficient. Of course, the results are approximate and somewhat idealized, however, the obtained data indicate that the proposed method of breaking will significantly reduce the specific consumption of explosives in the explosive destruction of strong rock masses. Therefore, this direction, with the development of means of mechanization, providing drilling and the formation of long horizontal charges of explosives, can be quite relevant and have practical significance.

Table 4. The results of the calculation of the DBO parameters for two options of the cut-off block technology

\begin{tabular}{|l|c|c|}
\hline \multirow{2}{*}{\multicolumn{1}{|c|}{ Index }} & \multicolumn{2}{|c|}{ Value } \\
\cline { 2 - 3 } & $\begin{array}{c}\text { Normal breaking } \\
\text { (first option) }\end{array}$ & $\begin{array}{c}\text { Breaking with the use of } \\
\text { horizontal cut on the bottom of } \\
\text { the bench (second option) }\end{array}$ \\
\hline Number of boreholes in the block, pcs. & 120 & 100 \\
\hline Drilling capacity, $\mathrm{m}$ & 2280 & 1900 \\
\hline Volume of block, $\mathrm{m}^{3}$ & 54000 & 54000 \\
\hline Number of explosives per block, $\mathrm{kg}$ & 84780 & 32532 \\
\hline Specific consumption of explosive, $\mathrm{kg} / \mathrm{m}^{3}$ & 1.57 & 0.6 \\
\hline
\end{tabular}




\section{Conclusions}

At present, in large open-pit mines, the distances between the boreholes are on the average 5-6 meters, and the size of the overdrills is from 2 to $3 \mathrm{~m}$. The analysis has showed that it is possible to increase the distance between the boreholes in strong rocks to 8-10 meters and a corresponding decrease in the specific consumption of explosives. However, this is possible only if the issue is solved with the development of the resistance line on the bottom of the bench. At large distances between the boreholes, the issue of developing the bottom is decisive.

The approximate calculations has shown that the use of the method of breaking the excavating block with horizontal cut along the bottom of the bench can be quite efficient. Developing the bottom of the bench with a horizontal cut and increasing the distances between vertical boreholes makes it possible to reduce both the volume of drilling and the consumption of explosives, the latter being by more than 2 times. Therefore, this direction is topical and can have high practical significance.

The research has been carried out within the framework of the State Proposal 00700293-18-00, themes No. 0405-2018-0015, No. 0405-2018-0001, project No. 18-5-5-10, as well as with additional attraction of contractual means.

\section{References}

1. I. F. Bondarenko, S. N. Zharikov, I. V. Zyryanov, V. G. Shemenyov, Blasting and Exploration Work at the Kimberlite Open-Pit Mines of Yakutia, (Moscow, 2017) 172 pp. [In Russian].

2. R. I. Sukhov, A. S. Regotunov, Bulletin of Scientific, Technical and Economic Information, Ferrous Metallurgy, 10, 22 (2017).

3. I. A. Tangaev, Energy Intensity of Mining and Processing of Minerals, (Moscow, 1986) 231 pp. [In Russian].

4. I. V. Vorontsov, A. A. Kotyashev, A. S. Matorin, V. G. Shemenyov, Izvestiya Vuzov, Mining Magazine, 8, 94 (2008).

5. S. N. Zharikov, V. G. Shemenyov, V. A. Kutuev, Sustainable Development of Mountain Territories 9, 74 (2017).

6. S. N. Zharikov, Interrelation of Specific Energy Characteristics of the Roller Drilling Processes and Explosive Destruction of the Rock Mass, (Ekaterinburg, 2011) 139 pp. [In Russian].

7. M. B. Togunov, Yu. A. Shitov, G. V. Melik-Gaykazov, V. A. Fokine, N. A. Sverdlenko, Mountain Magazine, 9, 40 (2007).

8. S. N. Zharikov, V. G. Shemenyov, Izvestiya Vuzov, Mining Magazine, 2, 80 (2013).

9. S. N. Zharikov, V. A. Kutuev, Deep Structure, Geodynamics, Thermal Field of the Earth, Interpretation of Geophysical Fields: Conference Materials. 179 pp. (2017) [In Russian].

10. V. A. Kuznetsov, Justification of Technology of Drilling and Blasting Operations in Open-Pit Mines and Open Mining and Construction Workings on the Basis of Deformation Zoning of Blasting Benches. 225 pp. (2010) [In Russian]. 